NASA TECHNICAL MEMORANDUM

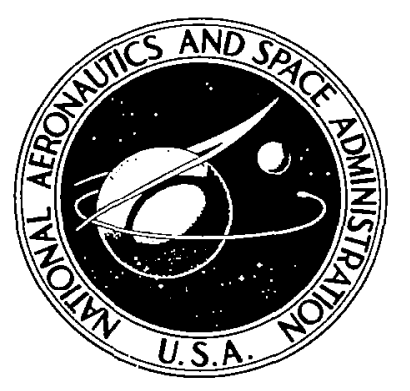

NASA TM X-2499

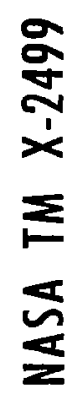

LOAN COPY: RETI AFWL (DOUIO)

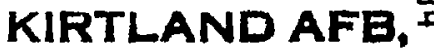

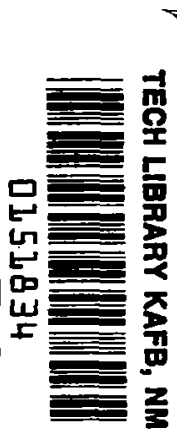

\title{
HIGH-TEMPERATURE CREEP \\ OF POLYCRYSTALLINE CHROMIUM
}

by jo ab K. Stephens and? William D. Klopp

E.eus Research Cute:

Cleveland, Obio 44135

National aeronautits aho SPACG adMINISTRation - Washington, D. C. - february 1972 
1. Report No.

NASA TM X-2499

4. Title and Subtitle

HIGH-TEMPERATURE CREEP OF POLYCRYSTALLINE CHROMIUM

7. Author(s)

Joseph R. Stephens and William D. Klopp

9. Performing Organization Name and Address

Lewis Research Center

National Aeronautics and Space Administration

Cleveland, Ohio 44135

12. Sponsoring Agency Name and Address

National Aeronautics and Space Administration

Washington, D. C. 20546
3. Recipient's Catalog No.

0151834

15. Supplementary Notes

16. Abstract

The creep properties of high-purity, polycrystalline chromium were determined over the temperature range 0.51 to $0.78 \mathrm{~T}_{\mathrm{m}}$, where $\mathrm{T}_{\mathrm{m}}$ is the melting temperature. Creep rates determined from step-load creep tests can be represented by the general creep equation

$$
\frac{\dot{\epsilon}}{\mathrm{D}}=\mathrm{k}\left(\frac{\sigma}{\mathrm{E}}\right)^{\mathrm{n}}
$$

where $\dot{\epsilon}$ is the minimum creep rate, $D$ is the diffusivity, $k$ is the creep rate constant, $\sigma$ is the applied stress, $\mathrm{E}$ is the modulus, and $\mathrm{n}$ is the stress exponent, equal to 4.3 for chromium. This correlation and metallographic observations suggest a dislocation climb mechanism is operative in the creep of chromium over the temperature range investigated.

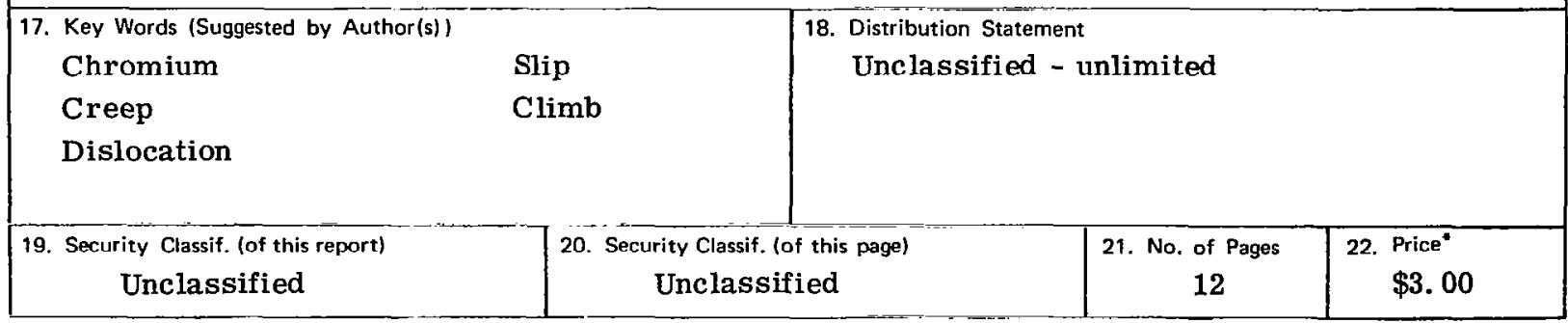

*For sale by the National Technical Information Service, Springfield, Virginia 22151 


\section{HIGH-TEMPERATURE CREEP OF POLYCRYSTALLINE CHROMIUM \\ by Joseph R. Stephens and William D. Klopp \\ Lewis Research Center}

\section{SUMMARY}

A study was conducted to determine the high-temperature creep properties of highpurity, polycrystalline chromium. Iodide chromium was consolidated into 100-gram buttons by arc-melting and fabricated to sheet by rolling. Test specimens machined from the wrought sheet were annealed in palladium-purified hydrogen in order to produce stable grain structures for testing. Chemical analysis indicated a total interstitial impurity content of less than $100 \mathrm{ppm}$. Step-load creep tests were conducted over the temperature range 0.51 to $0.78 \mathrm{~T}_{\mathrm{m}}$, where $\mathrm{T}_{\mathrm{m}}$ is the melting temperature.

Results showed that creep rates can be represented by the general creep equation

$$
\frac{\dot{\epsilon}}{D}=k\left(\frac{\sigma}{E}\right)^{n}
$$

where $\dot{\epsilon}$ is the minimum creep rate, $D$ is the diffusivity, $k$ is the creep rate constant, $\sigma$ is the applied stress, $\mathrm{E}$ is the modulus, and $\mathrm{n}$ is the stress exponent, equal to 4.3 for chromium. This correlation, which uses the previously determined activation energy of 0.306 megajoule per mole for self-diffusion in chromium, and observations of surface slip lines and dislocation substructures strongly suggest that a diffusioncontrolled, dislocation climb mechanism is operative in the creep of the chromium over the temperature range investigated.

\section{INTRODUCTION}

Although the high-temperature creep behavior of most of the body-centered-cubic metals from groups $\mathrm{V}$ and VI of the periodic table has been studied in some detail, very few data have been reported for chromium. Pugh (ref. 1) studied the tensile and stressrupture properties of arc-melted electrolytic chromium, but did not determine creep rates. Wilms and Rea (ref. 2) reported one creep rate for arc-melted electrolytic 
chromium at $950^{\circ} \mathrm{C}$. Landau, Greenaway, and Edwards (ref. 3) determined the compression creep rates for arc-melted electrolytic chromium at $750^{\circ}$ to $950^{\circ} \mathrm{C}$. In view of the paucity of tensile creep data for chromium and also of the interest in chromium as a potential turbine engine material, a study was conducted to determine in more detail the high-temperature creep properties of high-purity, polycrystalline chromium.

\section{MATERIALS AND PROCEDURE}

Chromium prepared by the iodide process was consolidated into 100-gram buttons by nonconsumable-electrode arc-melting under a partial pressure of argon. A titanium getter button was melted prior to the chromium to improve the purity of the melting atmosphere. The chromium buttons were subsequently remelted and drop cast under argon into a water-cooled copper mold of square cross section. The ingots were rolled to 0.09 -centimeter-thick sheet in air at $800^{\circ} \mathrm{C}$. Test specimens were machined from the wrought sheet with reduced sections 2.54 centimeter long by 0.635 centimeter wide. In order to produce stable grain structures for testing, the specimens were annealed in palladium-purified hydrogen for 1 hour at $1538^{\circ}$ or $1316^{\circ} \mathrm{C}$ and then purified by a 4-hour anneal at $1093^{\circ} \mathrm{C}$. Average grain diameters after these treatments were 0.090 and 0.023 centimeter, respectively.

Analysis after annealing indicated the following impurity contents, in parts per million: oxygen, 32; nitrogen, 58; carbon, <10; hydrogen, 0. 8; and iron, 20. Other metallic impurities were each $<10$ parts per million.

The creep tests were conducted in a beam-loaded unit equipped with a tantalum sleeve heater. Tests at $816^{\circ}$ and $982^{\circ} \mathrm{C}$ were conducted in a vacuum of $10^{-4}$ newton

per square meter $\left(10^{-6}\right.$ torr). Tests at $1149^{\circ}$ and $1316^{\circ} \mathrm{C}$ were conducted in high-purity argon at a pressure slightly greater than atmospheric in order to reduce vaporization losses of chromium.

All tests were conducted by incremental step loading in order to define the minimum creep rates over a range of stress conditions. Strain was continuously recorded by means of a linear variable differential transformer attached to the load train of the creep apparatus. Hot portions of the load train were made of tungsten in order to minimize extensions from these components. The specimen cross sections and gage lengths were corrected after each step load by assuming uniform strain in calculating creep rates and stresses.

\section{RESULTS}

Creep rate data are presented in table $I$, and lines obtained from a least squares fit of the data are shown in figure 1 . The creep rates can be represented as the power 
function of stress (ref. 4), which is expressed at constant temperatures as

$$
\dot{\epsilon}=\mathrm{k} \sigma^{\mathrm{n}}
$$

where

$\dot{\epsilon} \quad$ minimum creep rate, $\sec ^{-1}$

k creep rate constant

$\sigma \quad$ applied stress, $\mathrm{MN} / \mathrm{m}^{2}$

n stress exponent

The stress exponent decreases with increasing test temperature from 6.2 and 6.8 at $816^{\circ}$ and $982^{\circ} \mathrm{C}$, respectively, to 4.8 and 4.4 at $1149^{\circ}$ and $1316^{\circ} \mathrm{C}$, respectively. These values are consistent with observations on other metals (refs. 4 and 5), where values for $n$ of 4.5 to 5 are normally obtained above about $0.6 T_{m}\left(T_{m}\right.$ is melting temperature).

No strong relation between grain size and creep appears determinable from the present data. However, it appears from figure 1 that the coarse-grained specimens tend to creep faster than the fine-grained specimens. At $816^{\circ}, 1149^{\circ}$, and $1316^{\circ} \mathrm{C}$, the coarse-grained specimens crept as fast or faster than the fine-grained specimens, while at $982^{\circ} \mathrm{C}$, the fine-grained specimens crept faster. This trend towards higher creep rates for large-grained chromium is consistent with recent observations on tungsten (ref. 6) and other group Va and VIa metals (ref. 7).

In order to facilitate overall comparison, the data from the present study were compensated for temperature (diffusivity $\mathrm{D}$ ) and modulus $\mathrm{E}$ by introducing these terms into the power creep relation (ref. 5):

$$
\frac{\dot{\epsilon}}{\mathrm{D}}=\mathbf{k}\left(\frac{\sigma}{\mathrm{E}}\right)^{\mathrm{n}}
$$

Diffusivities were calculated from the data of Askill (ref. 8), while moduli were obtained from Armstrong and Brown (ref. 9).

A least squares fit of the compensated data as shown in figure 2 gives a straightline relation at ratios of $\dot{\epsilon}$ to $\mathrm{D}$ of less than $10^{8}$. The slope of this portion of the curve is 4.3 .

The rather good fit of the data below $\dot{\epsilon} / D$ equal to $10^{8}$ indicates that the activation energy of 0.306 megajoule per gram mole determined by Askill (ref. 8) for self-diffusion in chromium is also applicable to high-temperature creep. The upward swing of the curve at $\dot{\epsilon} / \mathrm{D}$ greater than $10^{8}$ is consistent with observations on other metals and re- 
flects both the gradual change to exponential dependency of creep rate on stress and the decrease in activation energy for creep which generally occur at about $0.5 \mathrm{~T}_{\mathrm{m}}$ (ref. 5). The creep data for arc-melted electrolytic chromium from Wilms and Rea (ref. 2) and Landau, Greenaway, and Edwards (ref. 3) are included in figure 2. This comparison indicates that the chromium from thes $\epsilon$ ino studies is substantially stronger than that from the present study, this difference possibly reflecting the lower purity of electrolytic chromium as compared to iodide chromium.

Surfaces of creep specimens were observed after testing by scanning electron microscopy (SEM). Figure 3 shows SEM photographs of specimens tested at $1316^{\circ}$ and $816^{\circ} \mathrm{C}$. As shown in figures $3(\mathrm{a})$ and (b), slip lines having an extremely small spacing are noted on specimens tested at the higher test temperature. According to a hypothesis by Weertman (ref. 10), creep controlled by dislocation climb could lead to the fine slip lines observed in figures $3(\mathrm{a})$ and (b). It is proposed that at high temperatures and low stresses a number of dislocation sources on different parallel planes generate dislocation loops which can climb and annihilate each other. Depending directly on the rate of climb, a steady stream of new dislocations would be generated from the various sources at a rate equal to annihilation so that slip would continue on many slip planes and the fine slip observed in figures $3(a)$ and (b) would result.

SEM photographs of a specimen tested at the lower test temperature are shown in figures $3(\mathrm{c})$ and (d), where a much coarser slip line spacing is evident. This suggests that the rate of dislocation climb and annihilation is less than the rate of dislocation generation at the lower-temperature, high-stress test conditions. This in turn would cause some dislocation sources to stop operating because of mutual repulsion of dislocations and thus produce slip on fewer slip planes; the fewer slip planes would result in the coarse slip line pattern shown in figures $3(c)$ and (d).

Creep specimens were further characterized by examination by transmission electron microscopy. A marked difference in substructure resulted as the test temperature increased. At the two higher test temperatures $\left(1316^{\circ}\right.$ and $\left.1149^{\circ} \mathrm{C}\right)$ well developed subgrains were present, as shown in figures $4(a)$ and (b). Of special interest in these micrographs is the absence of dislocations within the subgrains. This further supports ease of climb and annihilation of dislocations at the higher test temperatures. At the two lower test temperatures $\left(982^{\circ}\right.$ and $\left.816^{\circ} \mathrm{C}\right)$, the substructure was characterized by well defined subgrains with a relatively high concentration of dislocations within the subgrains, as shown in figures $4(\mathrm{c})$ and (d), which suggested more difficult dislocation motion at these temperatures.

In addition to the substructural features just described, the creep specimens were characterized by numerous tilt and twist boundaries, some of which are evident in figure 4. 


\section{CONCLUSIONS}

The following conclusions were drawn from a study of high-temperature creep of polycrystalline chromium:

1. Creep of chromium in the temperature range 0.51 to $0.78 T_{m}$, where $T_{m}$ is the melting temperature, and at ratios of $\dot{\epsilon} / \mathrm{D}$ less than $10^{8}$ can be represented by the general creep equation

$$
\frac{\dot{\epsilon}}{\mathrm{D}}=\mathrm{k}\left(\frac{\sigma}{\mathrm{E}}\right)^{\mathrm{n}}
$$

where $\dot{\epsilon}$ is the minimum creep rate, $D$ is the diffusivity, $k$ is the creep rate constant, $\sigma$ is the applied stress, $\mathrm{E}$ is the modulus, and $\mathrm{n}$ is the stress exponent, equal to 4. 3 for chromium.

2. This correlation, which uses the previously determined activation energy of 0.306 megajoule per mole for self-diffusion in chromium, and observations of surface slip lines and dislocation substructures strongly suggest that a diffusion-controlled, dislocation climb mechanism is operative in the creep of chromium over the temperature range investigated.

\section{Lewis Research Center,}

National Aeronautics and Space Administration, Cleveland, Ohio, November 15, 1971, 114-03.

\section{REFERENCES}

1. Pugh, J. W.: The Tensile and Stress-Rupture Properties of Chromium. Trans. ASM, vol. 50, 1958, pp. 1072-1080.

2. Wilms, G. R.; and Rea, T. W.: Preliminary Investigations on the Properties of Chromium and Chromium Alloys at Elevated Temperatures. J. Inst. Metals, vol. $87,1958-59$, pp. 77-78.

3. Landau, C. S.; Greenaway, H. T.; and Edwards, A. R.: Some Properties of Chromium and Chromium-Tungsten Alloys. I. - Compression Creep Tests.

J. Inst. Metals, vol. 89, 1960-61, pp. 97-101.

4. Garofalo, Frank: Fundamentals of Creep and Creep-Rupture in Metals. Macmillan Co., 1965, pp. 50 and 51. 
5. Robinson, S. L.; and Sherby, O. D.: Mechanical Behavior of Polycrystalline Tungsten at Elevated Temperature. Acta Met., vol. 17, no. 2, Feb. 1969, pp. 109125.

6. Klopp, William D.; Witzke, Walter R.; and Raffo, Peter L.: Effects of Grain Size on Tensile and Creep Properties of Arc-Melted and Electron-Beam-Melted Tungsten at $2250^{\circ}$ to $4140^{\circ}$ F. Trans. AIME, vol. 233, no. 10, Oct. 1965, pp. 18601866 .

7. Vandervoort, Richard R.: Creep Correlations for Bcc Refractory Metals. Trans. AIME, vol. 242, no. 2, Feb. 1968, pp. 345-34\%.

8. Askill, John: Tracer Diffusion Data for Metals, Alloys, and Simple Oxides. IFI/ Plenum, 1970, p. 32.

9. Armstrong, Philip E.; and Brown, Harry L.: Dynamic Young's Modulus Measurements above $1000^{\circ} \mathrm{C}$ on Some Pure Polycrystalline Metals and Commercial Graphites. Trans. AIME, vol. 230, no. 5, Aug. 1964, pp. 962-966.

10. Weertman, J.: Creep of Indium, Lead, and Some of Their Alloys With Various Metals. Trans. AIME, vol. 218, no. 2, Apr. 1960, pp. 207-218. 
TABLE I. - MINIMUM CREEP RATE DATA FOR CHROMIUM

\begin{tabular}{|c|c|c|c|c|c|c|c|c|c|}
\hline \multirow{2}{*}{$\begin{array}{c}\text { Temper- } \\
\text { ature, } \\
{ }^{\circ} \mathrm{C}\end{array}$} & \multirow{2}{*}{$\begin{array}{c}\text { Initial } \\
\text { grain } \\
\text { size, } \\
\mathrm{cm}\end{array}$} & \multicolumn{2}{|c|}{ Stress } & \multirow{2}{*}{$\begin{array}{l}\text { Minimum } \\
\text { creep rate, } \\
\text { sec }^{-1}\end{array}$} & \multirow{2}{*}{$\begin{array}{c}\text { Temper- } \\
\text { ature, } \\
{ }^{\circ} \mathrm{C}\end{array}$} & \multirow{2}{*}{$\begin{array}{c}\text { Initial } \\
\text { grain } \\
\text { size, } \\
\mathrm{cm}\end{array}$} & \multicolumn{2}{|c|}{ Stress } & \multirow{2}{*}{$\begin{array}{l}\text { Minimum } \\
\text { creep rate, } \\
\sec ^{-1}\end{array}$} \\
\hline & & $\mathrm{MN} / \mathrm{m}^{2}$ & ksi & & & & $\mathrm{MN} / \mathrm{m}^{2}$ & ksi & \\
\hline \multirow[t]{4}{*}{$a_{816}$} & \multirow[t]{2}{*}{0.023} & $\begin{array}{l}50.1 \\
61.2 \\
66.9 \\
72.5\end{array}$ & $\begin{array}{r}7.27 \\
8.87 \\
9.70 \\
10.52\end{array}$ & $\begin{array}{l}0.37 \times 10^{-6} \\
.94 \\
1.7 \\
3.5\end{array}$ & \multirow[t]{3}{*}{$c_{1149}$} & 0.023 & $\begin{array}{l}7.93 \\
11.5 \\
14.5 \\
18.6\end{array}$ & $\begin{array}{l}1.15 \\
1.67 \\
2.11 \\
2.70\end{array}$ & $\begin{array}{l}0.30 \times 10^{-6} \\
1.7 \\
4.8 \\
14\end{array}$ \\
\hline & & $\begin{array}{r}78.1 \\
84.6 \\
92.5 \\
100.5\end{array}$ & $\begin{array}{l}11.33 \\
12.27 \\
13.41 \\
14.57\end{array}$ & $\begin{array}{l}5.8 \\
8.0 \\
15 \\
31\end{array}$ & & \multirow[t]{2}{*}{0.090} & $\begin{array}{l}10.5 \\
11.1 \\
11.8\end{array}$ & $\begin{array}{l}1.52 \\
1.61 \\
1.71\end{array}$ & $\begin{array}{l}2.0 \times 10^{-6} \\
2.2 \\
2.4\end{array}$ \\
\hline & \multirow[t]{2}{*}{0.090} & $\begin{array}{l}54.9 \\
58.7 \\
63.1\end{array}$ & $\begin{array}{l}7.96 \\
8.51 \\
9.15\end{array}$ & $\begin{array}{l}0.79 \times 10^{-6} \\
1.5 \\
2.5\end{array}$ & & & $\begin{array}{l}12.9 \\
13.9 \\
15.4 \\
18.1\end{array}$ & $\begin{array}{l}1.81 \\
2.01 \\
2.23 \\
2.62\end{array}$ & $\begin{array}{r}2.8 \\
3.8 \\
9.1 \\
21\end{array}$ \\
\hline & & $\begin{array}{l}72.1 \\
82.7\end{array}$ & $\begin{array}{l}10.45 \\
12.00\end{array}$ & $\begin{array}{l}6.6 \\
22\end{array}$ & \multirow[t]{4}{*}{$d_{1316}$} & \multirow[t]{2}{*}{0.023} & 3.70 & 0.536 & $0.35 \times 10^{-6}$ \\
\hline \multirow[t]{3}{*}{$b_{982}$} & 0.023 & $\begin{array}{l}20.0 \\
21.2 \\
24.1 \\
27.4 \\
30.8\end{array}$ & $\begin{array}{l}2.90 \\
3.08 \\
3.50 \\
3.98 \\
4.46\end{array}$ & $\begin{array}{l}0.34 \times 10^{-6} \\
1.3 \\
1.7 \\
2.9 \\
4.8\end{array}$ & & & $\begin{array}{l}5.10 \\
5.01 \\
5.92 \\
7.45 \\
9.38 \\
11.6\end{array}$ & $\begin{array}{l}.727 \\
.859 \\
1.08 \\
1.36 \\
1.68\end{array}$ & $\begin{array}{l}1.5 \\
3.3 \\
7.3 \\
20 \\
65\end{array}$ \\
\hline & & $\begin{array}{l}34.5 \\
38.3 \\
42.6\end{array}$ & $\begin{array}{l}5.00 \\
5.55 \\
6.18\end{array}$ & $\begin{array}{l}9.8 \\
22 \\
51\end{array}$ & & \multirow[t]{2}{*}{0.090} & \multirow{2}{*}{$\begin{array}{l}5.04 \\
5.67 \\
6.61 \\
7.72\end{array}$} & \multirow{2}{*}{$\begin{array}{c}0.731 \\
.823 \\
.958 \\
1.12\end{array}$} & \multirow{2}{*}{$\begin{array}{l}2.8 \times 10^{-6} \\
4.2 \\
7.8 \\
10\end{array}$} \\
\hline & 0.090 & $\begin{array}{l}25.6 \\
30.1 \\
33.1 \\
36.5 \\
40.7 \\
45.4\end{array}$ & $\begin{array}{l}3.71 \\
4.36 \\
4.80 \\
5.30 \\
5.91 \\
6.58\end{array}$ & $\begin{array}{l}0.73 \times 10^{-6} \\
4.0 \\
6.2 \\
11 \\
24 \\
82\end{array}$ & & & & & \\
\hline
\end{tabular}

${ }^{\mathrm{a}}$ Calculated stress dependency $\mathrm{n}, 6.2$.

$\mathrm{b}_{\mathrm{n}}=6.8$.

$\mathrm{c}_{\mathrm{n}}=4.8$.

$d_{n}=4.4$. 


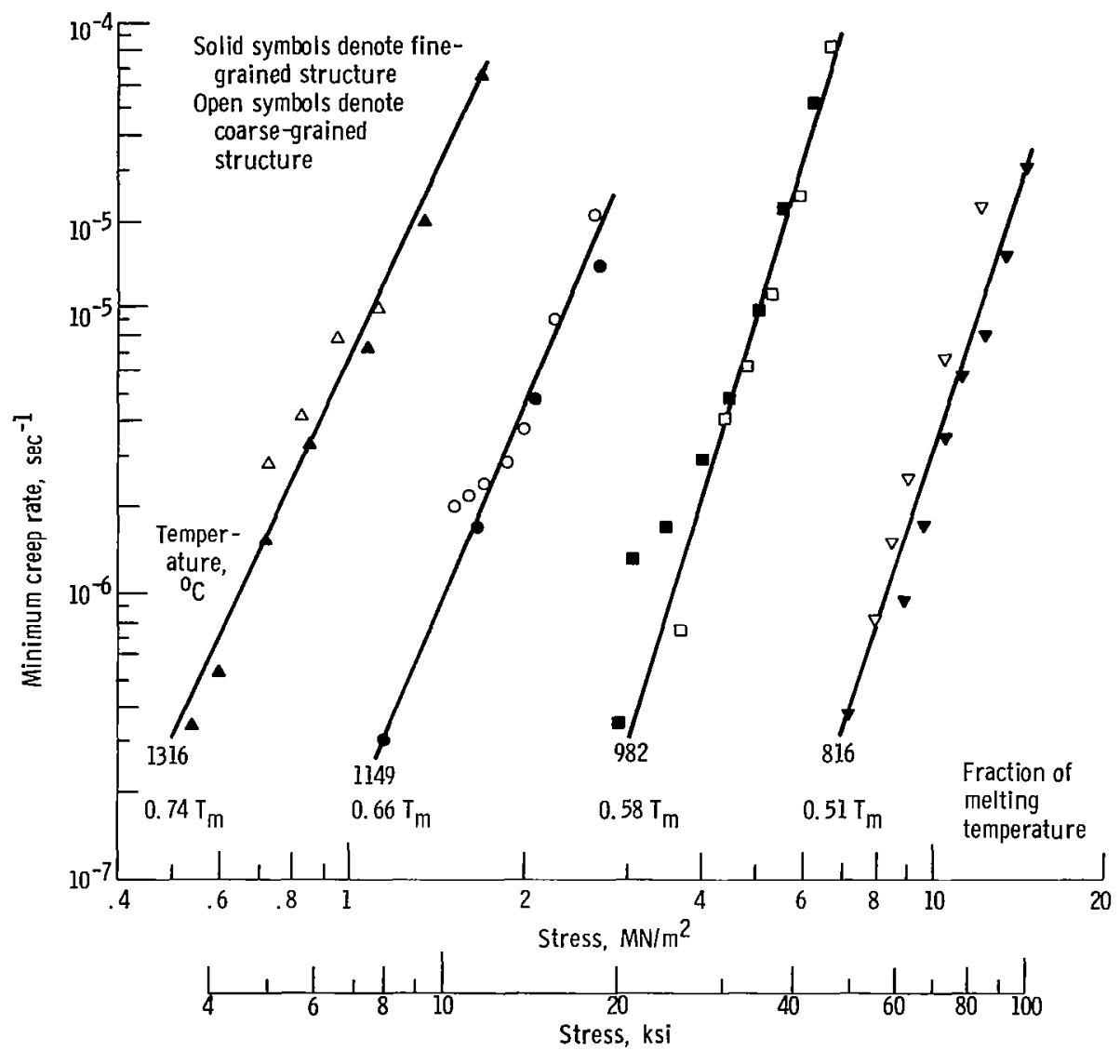

Figure 1. - Effects of stress and temperature on creep rates of chromium. 


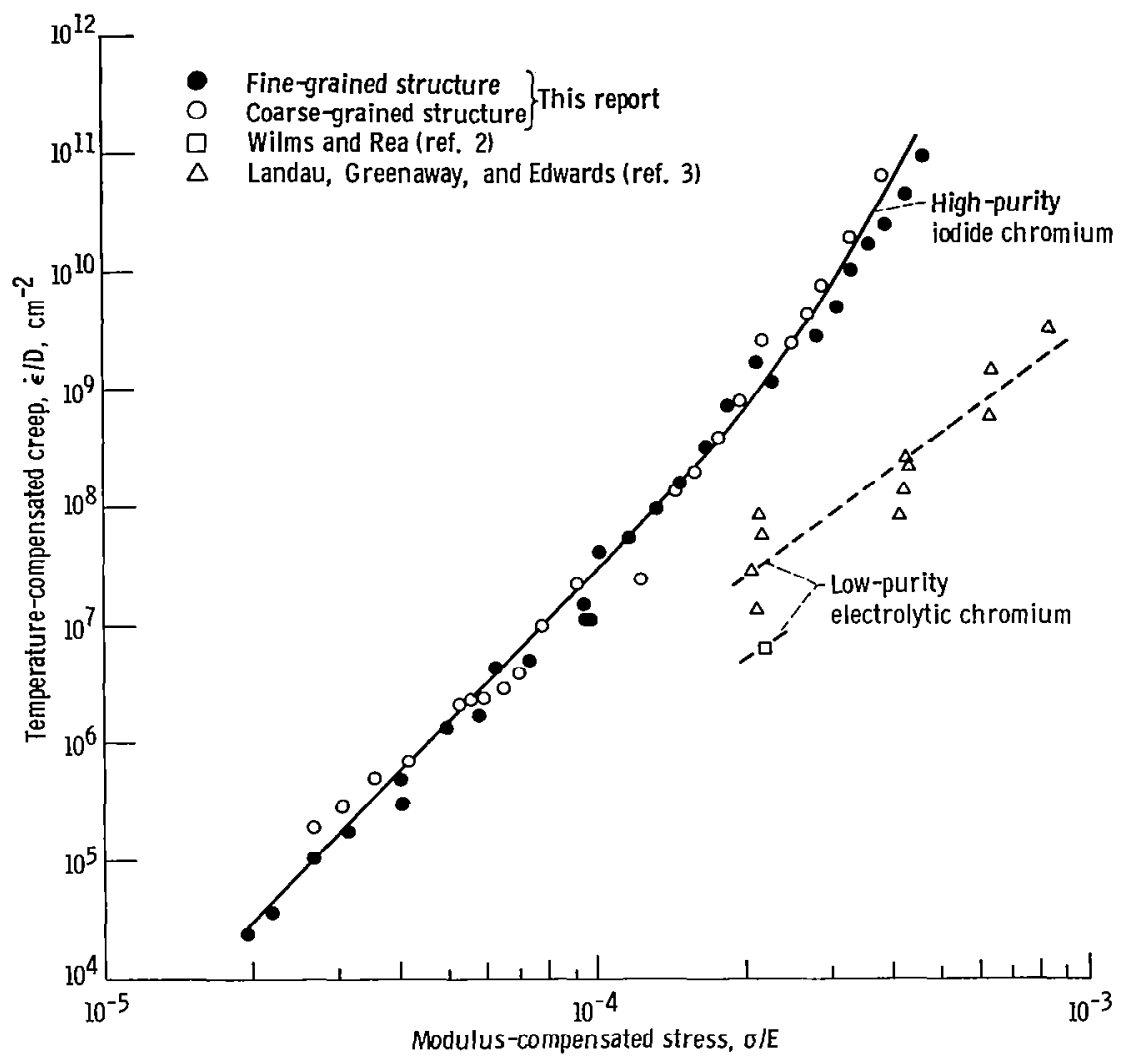

Figure 2. - Effects of modulus-compensated stress on temperature-compensated creep rates for chromium. 


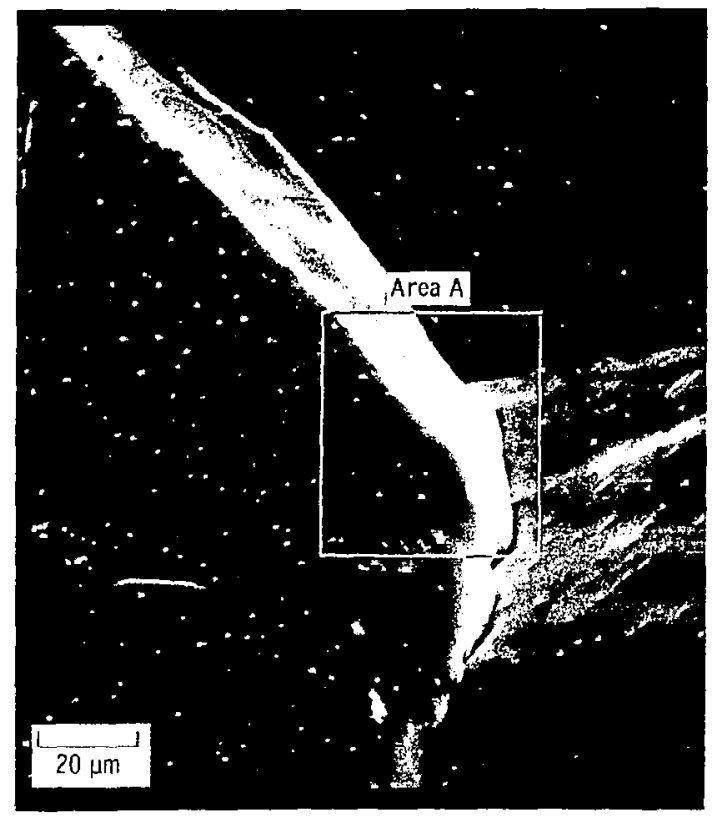

(a) Specimen tested at $1316^{\circ} \mathrm{C}(0.74$ of melting temperature) and applied stress of 11.6 meganewtons per square meter. $\times 600$.

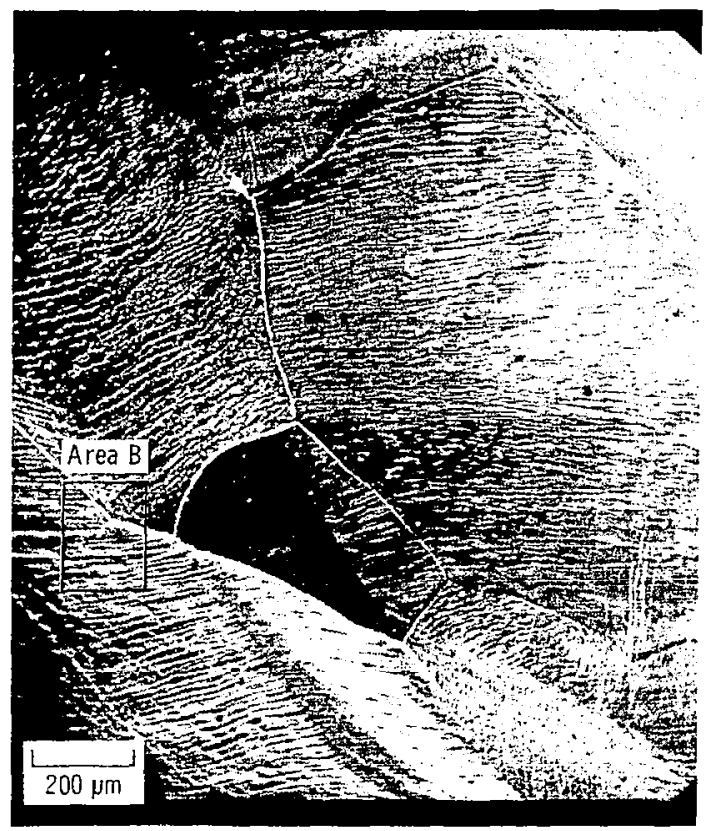

(c) Specimen tested at $816^{\circ} \mathrm{C}(0.51$ of melting temperature $)$ and applied stress of 100.5 meganewtons per square meter. $x 60$.

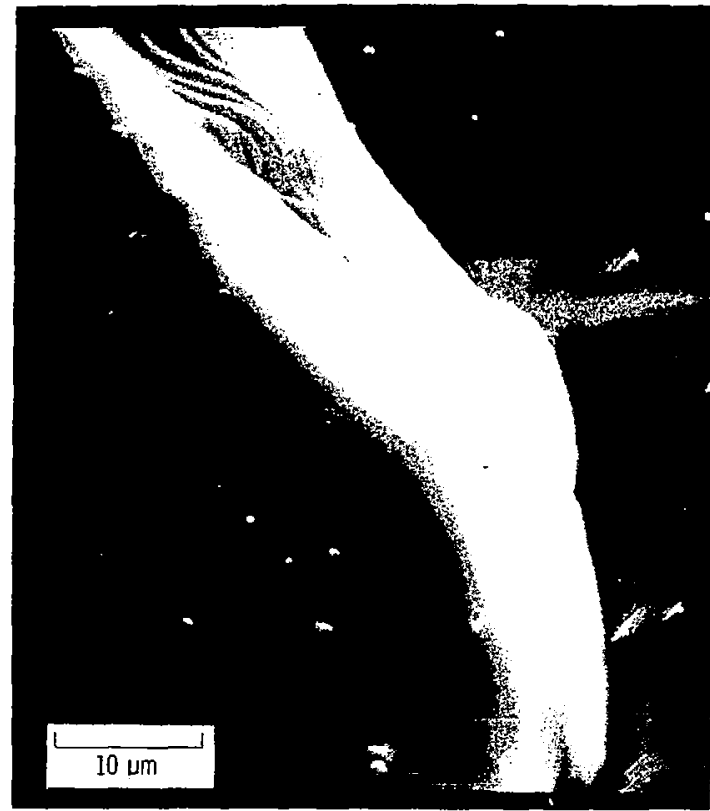

(b) Area A from specimen shown in (a). $X 1800$.

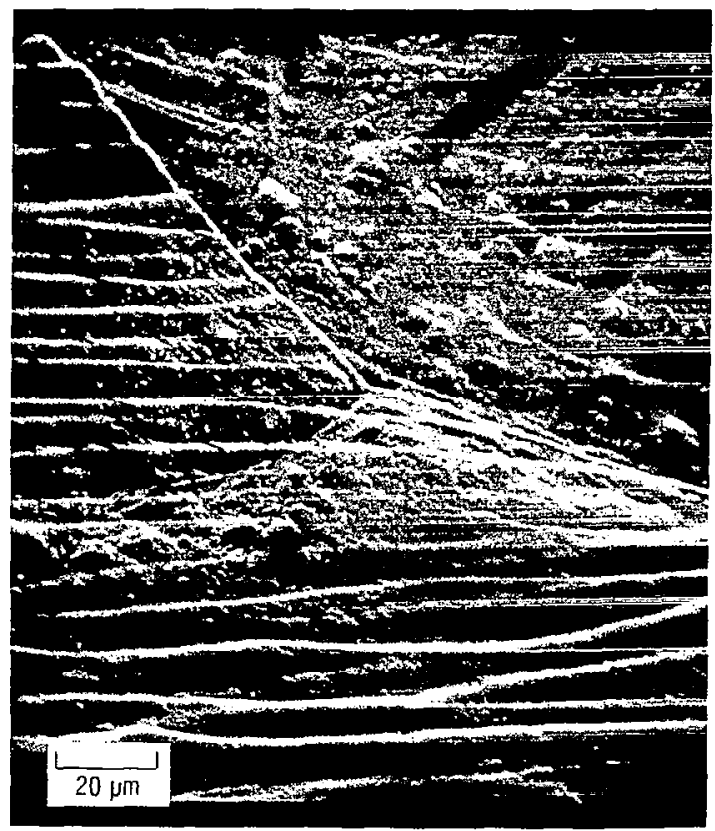

(d) Area B from specimen shown in (c). X600.

Figure 3. - Scanning electron micrographs of surfaces of chromium creep specimens illustrating slip lines. 


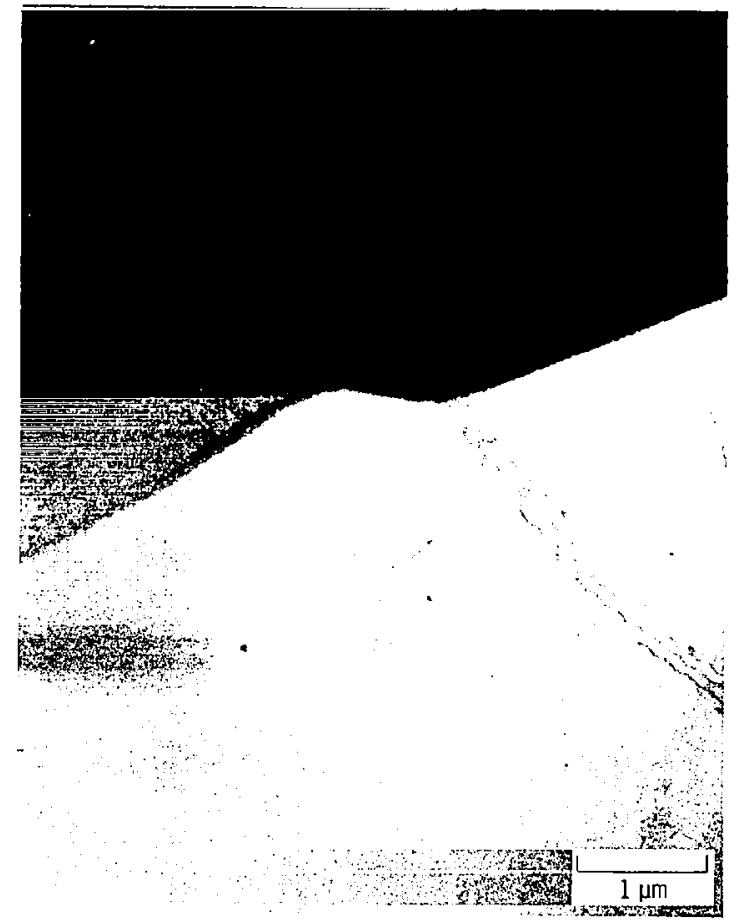

(a) Specimen tested at $1316^{\circ} \mathrm{C}(0.74$ of melting temperature).

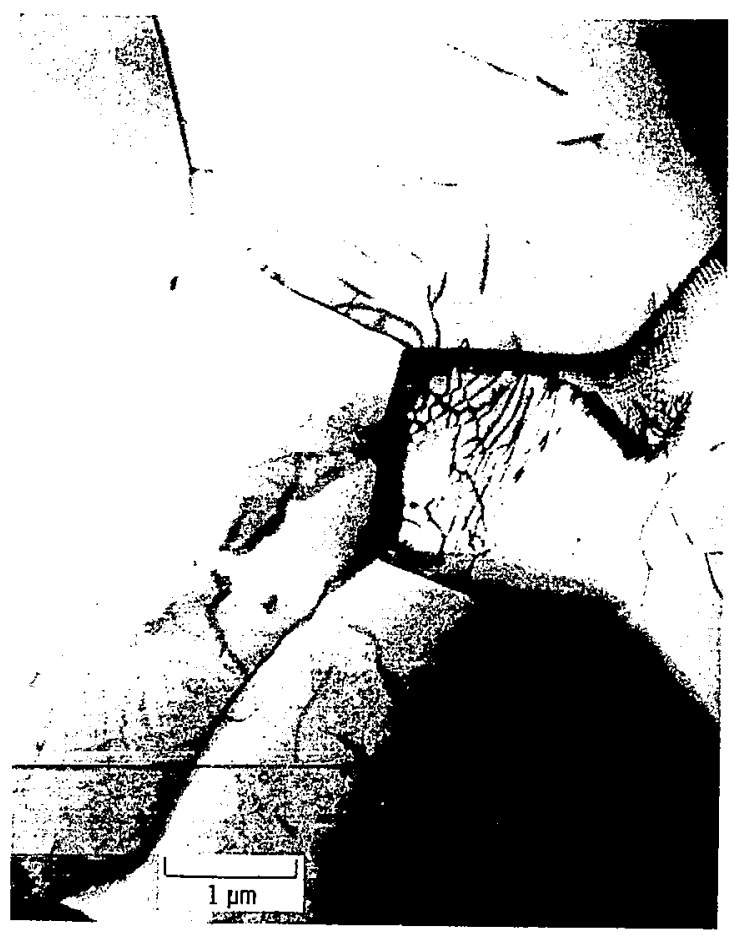

(c) Specimen tested at $982^{\circ} \mathrm{C}(0.58$ of melting temperature).

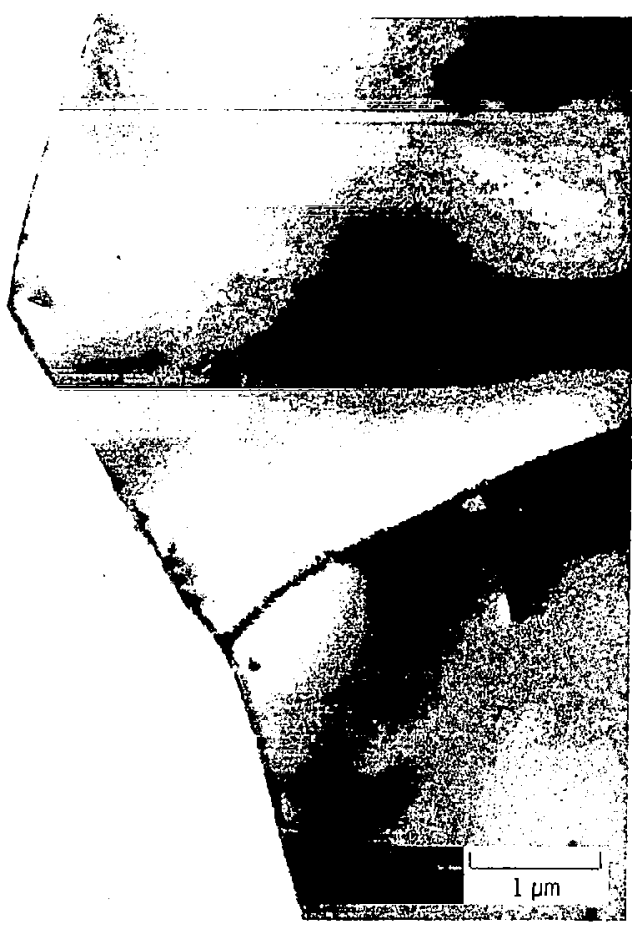

(b) Specimen tested at $1149^{\circ} \mathrm{C}(0.66$ of melting temperature).

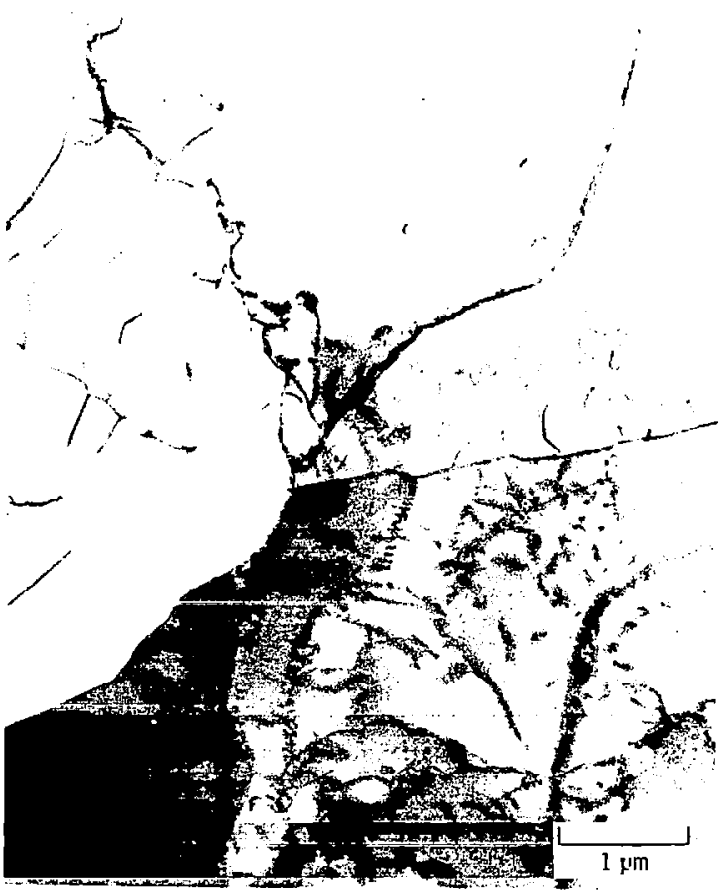

(d) Specimen tested at $816^{\circ} \mathrm{C}(0.51$ of melting temperature).

Figure 4. - Dislocation substructures observed in alloyed chromium after creep at various temperatures. X27 000 . 
036B 01 C2 UL $17 \quad 720128$ S00903DS

720401

DEPT OF THE AIR FORCE

AF WEAPONS LAB (AFSC)

TECH LIBRARY/WLOL/

ATTN: E LOU BOWMAN, CHTEF

KIRTLAND AFB NM 87117

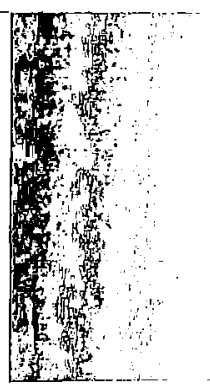

POSTMASTER: If Undeliverable (Section 158

"The acronautical and space activities of the United States shall bo conducted so as to contribute. . . to the expansion of buman knowledge of phenomena in the atmospbere and space. The Administration sball provide for the widest practicable and appropriate dissemination of information concerning its activities and the results thereof."

- National Aeronautics and Space ACt of 1958

\section{NASA SCIENTIFIC AND TECHNICAL PUBLICATIONS}

TECHNICAL REPORTS: Scientific and technical information considered important, complete, and a lasting contribution to existing knowledge.

TECHNICAL NOTES: Information less broad in scope but nevertheless of importance as a contribution to existing knowledge.

TECHNICAL MEMORANDUMS:

Information receiving limited distribution because of preliminary data, security classification, or other reasons.

CONTRACTOR REPORTS: Scientific and technical information generated under a NASA contract or grant and considered an important contribution to existing knowledge.
TECHNICAL TRANSLATIONS: Information published in a foreign language considered to merit NASA distribution in English.

SPECIAL PUBLICATIONS: Information derived from or of value to NASA activities. Publications include conference proceedings, monographs, data compilations, handbooks, sourcebooks, and special bibliographies.

TECHNOLOGY UTILIZATION PUBLICATIONS: Information on technology used by NASA that may be of particular interest in commercial and other non-aerospace applications. Publications include Tech Briefs, Technology Utilization Reports and Technology Surveys.

Details on the availability of these publications may be obtained from:

SCIENTIFIC AND TECHNICAL INFORMATION OFFICE

NATIONAL AERONAUTICS AND SPACE ADMINISTRATION Washington, D.C. 20546 